\title{
Investigation of methane adsorption on chlorite by grand canonical Monte Carlo simulations
}

\author{
Jian Xiong ${ }^{1} \cdot$ Xiang-Jun Liu $^{1} \cdot$ Li-Xi Liang ${ }^{1} \cdot$ Qun Zeng $^{2}$
}

Received: 8 April 2016/Published online: 7 January 2017

(c) The Author(s) 2017. This article is published with open access at Springerlink.com

\begin{abstract}
In this paper, the methane adsorption behaviours in slit-like chlorite nanopores were investigated using the grand canonical Monte Carlo simulation method, and the influences of the pore sizes, temperatures, water, and compositions on methane adsorption on chlorite were discussed. Our investigation revealed that the isosteric heat of adsorption of methane in slit-like chlorite nanopores decreased with an increase in pore size and was less than $42 \mathrm{~kJ} / \mathrm{mol}$, suggesting that methane adsorbed on chlorite through physical adsorption. The methane excess adsorption capacity increased with the increase in the pore size in micropores and decreased with the increase in the pore size in mesopores. The methane excess adsorption capacity in chlorite pores increased with an increase in pressure or decrease in pore size. With an increase in temperature, the isosteric heats of adsorption of methane decreased and the methane adsorption sites on chlorite changed from lowerenergy adsorption sites to higher-energy sites, leading to the reduction in the methane excess adsorption capacity. Water molecules in chlorite pores occupied the pore wall in a directional manner, which may be related to the van der Waals and Coulomb force interactions and the hydrogen bonding interaction. It was also found that water molecules existed as aggregates. With increasing water content, the water molecules occupied the adsorption sites and
\end{abstract}

Jian Xiong

361184163@qq.com

1 State Key Laboratory of Oil and Gas Reservoir Geology and Exploitation, Southwest Petroleum University, Chengdu 610500, Sichuan, China

2 Institute of Chemical Materials, Engineering Physical Academy of China, Mianyang 621999, Sichuan, China

Edited by Jie Hao adsorption space of the methane, leading to a reduction in the methane excess adsorption capacity. The excess adsorption capacity of gas on chlorite decreased in the following order: carbon dioxide $>$ methane $>$ nitrogen. If the mole fraction of nitrogen or carbon dioxide in the binary gas mixture increased, the mole fraction of methane decreased, methane adsorption sites changed, and methane adsorption space was reduced, resulting in the decrease in the methane excess adsorption capacity.

Keywords Chlorite · Methane · Nanopores · Grand canonical Monte Carlo · Adsorption capacity

\section{Introduction}

The study "Technically Recoverable Shale Oil and Shale Gas Resources: An Assessment of 137 Shale Formations in 41 Countries outside the United States" conducted by the US DOE's Energy Information Administration (EIA) in 2013, indicated that technically the shale gas resource in the world was approximately $220 \times 10^{12} \mathrm{~m}^{3}$, suggesting that there was a significant developmental potential for shale gas resources in the world (EIA 2013). Free, adsorbed, and dissolved gases exist in shale formations. Adsorbed gas is found on the surface of the mineral grains or in the micropore structure of organic matter in shale gas reservoirs. However, free gas is mainly contained in microfractures or larger pores in organic matter as well as in mineral grains in shale gas reservoirs. In 2002, Curtis studied the characteristics of American shale gas reservoirs, drawing the conclusion that adsorbed gas accounts for approximately $20 \%-85 \%$ of the total gas content and suggesting that adsorbed gas played an important role in the shale gas resource. Therefore, it is important to 
investigate the methane adsorption capacity of organic-rich shales to evaluate shale gas resources. Both the physicochemical properties of shales and environmental factors could have an impact on the methane adsorption capacity of shales, illustrating that the mineralogical compositions are key factors that affect the methane adsorption capacity of shales. According to previous research (Liang et al. 2015; Liu et al. 2015; Xiong et al. 2015a), clay minerals are the essential mineralogical components of the shales from the Yanchang Formation of the Ordos Basin as well as the Longmaxi Formation and Wufeng Formation of the Sichuan Basin, the contents of which were comparatively higher. Therefore, it is important to investigate the methane adsorption capacity on chlorite, which is an important type of clay mineral. Currently, studies aimed at evaluating the methane adsorption capacity on chlorite mainly focused on isothermal adsorption experiments. Ji et al. (2012a, b) investigated the influences of pressure, temperature, and grain size on the methane adsorption capacity of chlorite. Fan et al. (2014) studied the influences of pressure and temperature on the methane adsorption capacity of chlorite. Tang and Fan (2014) studied the methane adsorption capacity of chlorite at different temperatures under a pressure of $20 \mathrm{MPa}$. Liang et al. (2016) investigated the methane adsorption capacity of chlorite under a pressure of $20 \mathrm{MPa}$. All of the above studies were based on isothermal adsorption experiments, that is, the value of the adsorption amount under equilibrium pressure can be used to evaluate the methane adsorption capacity of chlorite. However, this value comprehensively reflects the specific surface area of chlorite and the value of the adsorption amount per unit surface area and cannot fundamentally reflect the essence of microscopic adsorption mechanisms of the methane adsorption on the chlorite owing to the results obtained for the macroscopic behaviour.

Computational molecular simulations have recently attracted much attention as a theoretical research method that can be used to study the adsorption properties of the adsorbent and could therefore be used to investigate the adsorption mechanism of fluid molecules on porous material. Titiloye and Skipper (2005) used the grand canonical Monte Carlo (GCMC) and molecular dynamics (MD) methods to study the adsorption behaviours and structural properties of methane in slit-like montmorillonite pores. Using MD simulations, the microscopic structural properties and diffusion behaviours of carbon dioxide in slit-like montmorillonite pores were studied by Yang and Zhang (2005). Jin and Firoozabadi $(2013,2014)$ used GCMC to investigate the adsorption behaviours of methane and carbon dioxide in slitlike montmorillonite pores as well as the influence of water on the adsorption behaviours of methane and carbon dioxide. Using the GCMC method, Sun et al. (2015) performed research on the methane adsorption behaviours of different types of clay minerals (montmorillonite, illite and kaolinite) and also studied the effects of different temperatures on the methane adsorption behaviours. Sui et al. (2015) studied the microscopic structural properties and diffusion behaviours of methane in slit-like montmorillonite pores using the GCMC and MD methods. Xiong et al. (2016) studied the microscopic adsorption mechanism of methane in slit-like montmorillonite pores using the GCMC method. These studies generated knowledge on methane adsorption on montmorillonite, illite and kaolinite. However, the detailed microscopic adsorption mechanism of methane in chlorite pores has not been well studied.

Hence, this article regarded chlorite as an object of study and used the computer molecular simulation technique to construct skeleton patterns of slit-like chlorite pores. Then, the impacts of pore sizes, temperatures, water and gas compositions on the methane adsorption behaviours in slitlike chlorite pores and the microscopic adsorption mechanism of methane in chlorite pores were studied using the GCMC simulations. Finally, the influence of the temperatures, water contents and compositions on the adsorption behaviours of methane on chlorite and their interaction mechanisms were discussed, which can provide important theoretical and instructional significance for the exploration and development of shale gas reservoirs.

\section{Molecular model}

The parameters of the chlorite crystal cell can be found in the literature (Joswig et al. 1980). The following parameters from this crystal cell are listed: $a=0.5327 \mathrm{~nm}$, $b=0.9232 \mathrm{~nm}, c=1.440 \mathrm{~nm}, \alpha=\gamma=90^{\circ}, \beta=97.16^{\circ}$. According to the $9 a \times 4 b$ super-cell structure constructed in the $x$ and $y$ directions of the chlorite unit crystal cell structure, the size of this super-cell structure in the $x \times y$ direction is $4.794 \mathrm{~nm} \times 3.693 \mathrm{~nm}$. Based on this, a space can be added in the $z$ direction between the two super-cell structures to construct pores with different sizes in the chlorite super-cell structure. Figure 1 shows the configuration of the slit-like chlorite pore, and Table 1 presents their basic parameters.

The Lennard-Jones (L-J) potential parameters and charges of the sites in the unit cell of chlorite are presented in Table 2 and are taken from the work of Cygan et al. (2004) and Jin and Firoozabadi (2013, 2014). Methane and nitrogen molecules were modelled using a TraPPE force field (Martin and Siepmann 1998; Potoff and Siepmann 2001), the water molecule was modelled using an SPC-E force field (Berendsen et al. 1987), and the carbon dioxide molecule was simulated by using the EPM2 model (Harris and Yung 1995). All fluid molecules retain electric neutrality. The L-J potential parameters and charges of each atom in the liquids 


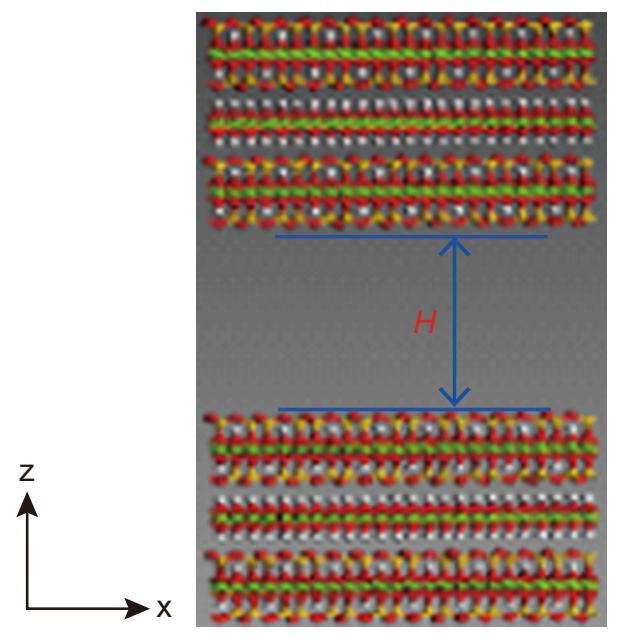

Fig. 1 Schematic representation of the slit-like chlorite pore ( $H$ represents different pore sizes) (red circle is oxygen atom, white circle is hydrogen atom, yellow circle is silicon atom, purple circle is aluminium atom, green circle is magnesium atom)

are also shown in Table 2 and can be found in the above references. During the simulation, the force fields are based on the Dreiding force field, and chlorite is supposed to be a rigid body. Furthermore, owing to the lack of force fields for magnesium, we assign the same L-J parameters for magnesium as for aluminium in the Dreiding force field (Zeng et al. 2003; Jin and Firoozabadi 2013). In addition, the charges of magnesium and aluminium are +2 and +3 , respectively. In the simulation, the interactions consist of the van der Waals force and Coulomb force. The L-J (12-6) potential model was used to describe the van der Waals force. The model to represent the Coulomb force and van der Waals force is given by:

$E=\varepsilon_{i j}\left[\left(\frac{\sigma_{i j}}{r_{i j}}\right)^{12}-\left(\frac{\sigma_{i j}}{r_{i j}}\right)^{6}\right]+\frac{q_{i} q_{j}}{4 \pi \varepsilon_{0} r_{i j}}$.

where $q_{i}, q_{j}$ are the charges of atoms in the system in C; $r_{i j}$ is the distance between the atoms $i$ and $j$ in $\mathrm{nm} ; \varepsilon_{0}$ is the dielectric constant, $8.854 \times 10^{-12} \mathrm{~F} / \mathrm{m}$; and $\sigma_{i j}$ and $\varepsilon_{i j}$ are the L-J potential parameters. According to the LorentzBotherlot mixed rules these are set as:

$\sigma_{i j}=\left(\sigma_{i}+\sigma_{j}\right) / 2 \quad \varepsilon_{i j}=\sqrt{\varepsilon_{i} \times \varepsilon_{j}}$

where $\sigma_{i}, \sigma_{j}$ are the collision diameters of the atoms or molecules $i, j$ in nm and $\varepsilon_{i}, \varepsilon_{j}$ are the potential well depths in $\mathrm{kJ} / \mathrm{mol}$.

\section{Simulation method}

\subsection{Grand canonical Monte Carlo (GCMC)}

Monte Carlo simulations have been widely used to study the adsorption properties of materials, while GCMC has been widely applied in the investigation of the adsorption behaviours of an adsorbate on an adsorbent. In this work, we use GCMC simulation to investigate the adsorption behaviours of methane in a slit-like chlorite pore. In the grand canonical ensemble, the chemical potential, volume, and temperature are the independent variables. Among these, the chemical potential is a function of the fugacity instead of the pressure. In this research, the Soave, Redlich and Kwong (SRK) state equation was used to calculate the fugacity (Soave 1972). The fugacity coefficients of pure methane at different temperatures and pressures in the simulations are shown in Fig. 2a, and the fugacity coefficients of the mole fraction of methane in the binary gas mixture at different pressures in the simulations are described in Fig. 2b, c. Simulation of the methane isothermal adsorption by the GCMC method was performed mainly using Sorption Module of the Materials Studio 6.0. The temperature in this simulation varied from 313 to $373 \mathrm{~K}$, and the temperature interval was $20 \mathrm{~K}$. The maximum simulated pressure was $40 \mathrm{MPa}$, and the simulation was under constant pressure, point by point, divided into a total of 15 points. The force field type used in this

Table 1 Parameters of the slit-like chlorite pore of different pore sizes

\begin{tabular}{|c|c|c|c|c|c|c|c|c|c|c|}
\hline$H, \mathrm{~nm}$ & $x, \mathrm{~nm}$ & $y, \mathrm{~nm}$ & $z, \mathrm{~nm}$ & $\alpha$ & $\beta$ & $\gamma$ & Surface area, $\times 10^{-17} \mathrm{~m}^{2}$ & Volume, $\times 10^{-20} \mathrm{~cm}^{3}$ & Density, $\mathrm{g} / \mathrm{cm}^{3}$ & Mass, $\times 10^{-19} \mathrm{~g}$ \\
\hline 1 & 4.794 & 3.693 & 5.227 & 90 & 97.16 & 90 & 1.77 & 9.727 & 2.292 & 2.23 \\
\hline 1.5 & 4.794 & 3.693 & 5.727 & 90 & 97.16 & 90 & 1.77 & 10.61 & 2.101 & 2.23 \\
\hline 2 & 4.794 & 3.693 & 6.227 & 90 & 97.16 & 90 & 1.77 & 11.50 & 1.940 & 2.23 \\
\hline 3 & 4.794 & 3.693 & 7.227 & 90 & 97.16 & 90 & 1.77 & 13.27 & 1.681 & 2.23 \\
\hline 4 & 4.794 & 3.693 & 8.227 & 90 & 97.16 & 90 & 1.77 & 15.04 & 1.483 & 2.23 \\
\hline 6 & 4.794 & 3.693 & 10.227 & 90 & 97.16 & 90 & 1.77 & 18.58 & 1.200 & 2.23 \\
\hline 8 & 4.794 & 3.693 & 12.227 & 90 & 97.16 & 90 & 1.77 & 22.12 & 1.008 & 2.23 \\
\hline 10 & 4.794 & 3.693 & 14.227 & 90 & 97.16 & 90 & 1.77 & 25.66 & 0.869 & 2.23 \\
\hline 15 & 4.794 & 3.693 & 19.227 & 90 & 97.16 & 90 & 1.77 & 34.51 & 0.646 & 2.23 \\
\hline 20 & 4.794 & 3.693 & 24.227 & 90 & 97.16 & 90 & 1.70 & 43.36 & 0.514 & 2.23 \\
\hline
\end{tabular}


Table 2 L-J potential parameters and charges of each atom

\begin{tabular}{llllll}
\hline & Atoms & $\varepsilon / k_{B}, \mathrm{~K}$ & $\sigma, \mathrm{nm}$ & $q, \mathrm{e}$ & References \\
\hline Chlorite & $\mathrm{O}(t)$ & 78.18 & 0.3166 & -0.800 & Cygan et al. (2004), Jin and \\
& $\mathrm{O}(a)$ & 78.18 & 0.3166 & -1.000 & Firoozabadi (2013, 2014) \\
& $\mathrm{O}(o)$ & 78.18 & 0.3166 & -1.7175 & -1.7175 \\
& $\mathrm{O}(\mathrm{OH})$ & 78.18 & 0.3166 & 0.7175 & 1.200 \\
& $\mathrm{H}(\mathrm{OH})$ & 0.00 & 0.0000 & 3.000 & Martin and Siepmann (1998) \\
& $\mathrm{Si}$ & $9.26 \times 10^{4}$ & 0.3302 & 2.000 & Berendsen et al. (1987) \\
Methane & $\mathrm{Al}$ & $4.54 \times 10^{4}$ & 0.5086 & 0 & Harris and Yung (1995) \\
Water & $\mathrm{Mg}$ & $4.54 \times 10^{4}$ & 0.5086 & -0.8476 & Potoff and Siepmann (2001) \\
Carbon dioxide & $\mathrm{C}$ & 148.10 & 0.3730 & 0.4238 & 0.6512 \\
& $\mathrm{O}$ & 78.18 & 0.3166 & -0.3256 & -0.482 \\
Nitrogen & $\mathrm{H}$ & 0 & 0 & 0.964 & \\
\hline
\end{tabular}

Notes: $(t)$ tetrahedron oxygen, $(o)$ octahedral oxygen, $(a)$ terminal oxygen, COM at the centre of the nitrogen-nitrogen bond
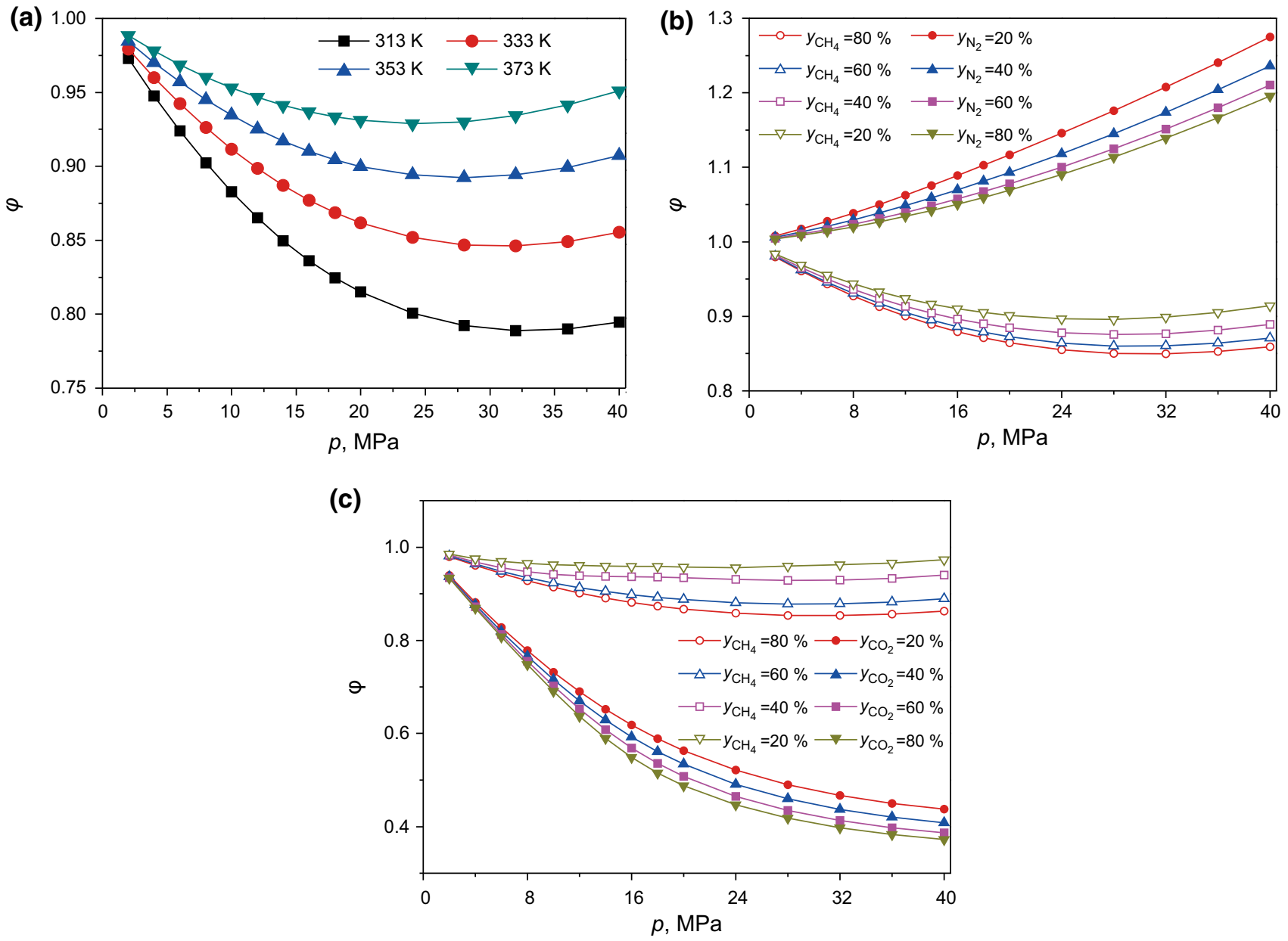

Fig. 2 Methane fugacity coefficient at different temperatures and pressures 
simulation was the Dreiding force field, with the Coulomb force and van der Waals force interactions calculated by the Ewald \& Group method and the atom interaction-based method with an L-J potential cutoff distance of $1.55 \mathrm{~nm}$. The maximum number of load steps in each simulation was $3 \times 10^{6}$, including $1.5 \times 10^{6}$ balance steps and $1.5 \times 10^{6}$ process steps. The related statistics were obtained using the later $1.5 \times 10^{6}$ configurations.

\subsection{Excess adsorption amount}

The isothermal adsorption experiments of the chlorite exceed the critical temperature of methane (191 K), suggesting that the methane adsorption behaviour on chlorite belongs to supercritical adsorption. For supercritical adsorption, Gibbs proposed that an adsorbate molecule in the adsorbed phase on the surface of the adsorbent cannot be used as the total adsorption amount. Additionally, the distribution of adsorbate molecules in the adsorbed phase based on the gas phase density was independent of the gas/solid molecule inter-atomic forces (Xiong et al. 2015b). According to this view, Gibbs introduced the concept of the excess adsorption amount:

$n_{\mathrm{ex}}=n_{\mathrm{ab}}-\rho_{\mathrm{g}} V_{\mathrm{a}}$,

where $n_{\mathrm{ex}}$ is the excess adsorption amount in mol/g, $n_{\mathrm{ab}}$ is the absolute adsorption amount in $\mathrm{mol} / \mathrm{g}, V_{\mathrm{a}}$ is the adsorbed phase volume in $\mathrm{cm}^{3}$, and $\rho_{\mathrm{g}}$ is the vapour density in $\mathrm{g} / \mathrm{cm}^{3}$ calculated by the SRK state equation (Soave 1972).

Figure 3 shows a schematic representation of the excess adsorption amount and absolute adsorption amount in which the area of $a$ represents the excess adsorption amount and the total area of $a$ and $b$ expresses the absolute adsorption amount. We assume that the total amount of adsorbate in the adsorption system is $N$, corresponding to the total area of $a, b$, and $c$, as shown in Fig. 3, which is equal to the expression $\left(n_{\mathrm{ab}}+\rho_{\mathrm{g}} V_{\mathrm{g}}\right)$. Therefore,

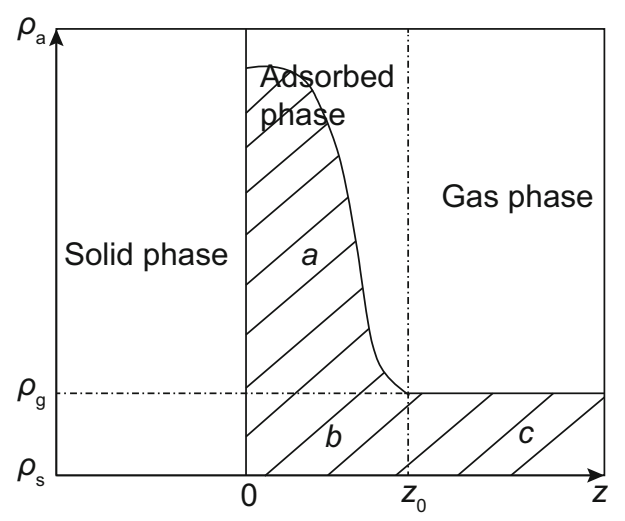

Fig. 3 Schematic representation of the excess adsorption amount and absolute adsorption amount
$\rho_{\mathrm{g}}\left(V_{\mathrm{a}}+V_{\mathrm{g}}\right)$ represents the total area of $b$ and $c$, as shown in Fig. 2. Then, the excess adsorption amount can be expressed as follows:

$n_{\mathrm{ex}}=N-\rho_{\mathrm{g}}\left(V_{\mathrm{a}}+V_{\mathrm{g}}\right)=N-\rho_{\mathrm{g}} V_{\mathrm{p}}$

where $N$ is the total amount of gas in $\mathrm{mol} / \mathrm{g}, V_{\mathrm{g}}$ is the gas phase volume in $\mathrm{g} / \mathrm{cm}^{3}$, and $V_{\mathrm{p}}$ is the free volume in $\mathrm{g} / \mathrm{cm}^{3}$. The free volume in the pore can be determined by the method that uses He as the probe (Talu and Myers 2001). Therefore, the gas amount obtained from the results of the simulation is the total amount of gas, and based on the free volume in the pore, the total amount of gas can be converted into the excess adsorption amount of the gas according to Eq. (4).

\section{Results and discussions}

\subsection{Influences of different pore sizes}

Figure 4 presents the total amount and excess adsorption capacity isotherms of methane in chlorite pores for different pore sizes. Examination of Fig. 4a shows that the total amount of methane increased with the increment of the pore size and first increased rapidly and then increased slowly with the increase in pressure. At the same time, from Fig. $4 b$, it can be seen that the differences among the excess adsorption capacity of methane on chlorite in micropores were small. However, it also showed that the methane excess adsorption capacity gradually decreased as the pore size increased in the mesopores, and the excess adsorption capacity of methane in mesopores is significantly smaller than that in micropores. This may be because the potential superimposed effect of the pore wall can significantly affect the adsorption of methane molecules in micropores, and the methane adsorption capacity in the pore would therefore be limited by the pore volume, that is, the pore volume increases with the increase in the pore size and methane adsorption capacity. However, the adsorption of methane molecules in mesopores was mainly affected by the surface potential effect of the two sides of the pore wall; the interactions between the methane molecules and the chlorite decrease, and movement space of the methane molecules increases, which makes the force to escape from the chlorite pore wall easy to overcome. Then, the methane adsorption capacity decreases with increasing pore size. In addition, the excess adsorption capacity of methane first increased after the pressure drop. That is, there is a maximum value of the excess adsorption capacity $\left(n_{\text {exc-max }}\right)$, and the corresponding pressure is known as the maximum pressure $\left(p_{\max }\right)$. This conclusion is in line with that of previous studies of organic-rich shales (Rexer et al. 2013; Gasparik et al. 2014; Yang et al. 2015). 

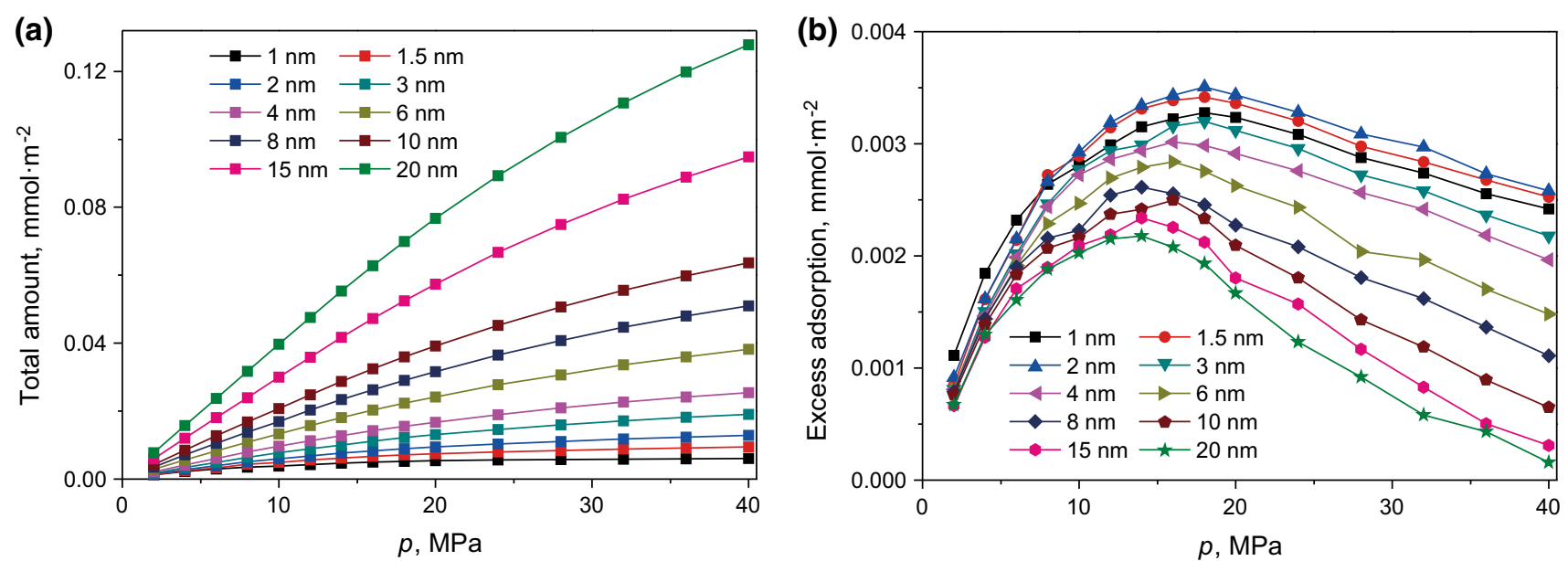

Fig. 4 Total amount isotherms of methane (a) and the excess adsorption isotherms of methane (b) in chlorite pores for different pore sizes (temperature of $333 \mathrm{~K}$ )

Table 3 shows the maximum values of the methane excess adsorption capacity and its corresponding pressure for different pore sizes. Examination of the data in Table 3 shows that the maximum pressure corresponding to the maximum value of the excess adsorption capacity was different and that the range of the maximum pressure was between $14 \mathrm{MPa}$ and $18 \mathrm{MPa}$. This finding is in agreement with previous studies on organic-rich shales (Rexer et al. 2013; Gasparik et al. 2014; Yang et al. 2015), suggesting that the maximum pressure $\left(p_{\max }\right)$ was between 10 and $19 \mathrm{MPa}$, as was concluded from the experimental data. This result indicates that, to a certain extent, our simulation results are in reasonable agreement with the experimental results. Meanwhile, the maximum value of the excess adsorption capacity decreased with an increase in pore size in mesopores. The maximum value of the excess adsorption capacity reached a peak value of $0.00372 \mathrm{mmol} / \mathrm{m}^{2}$ when the pore size was $2 \mathrm{~nm}$, while the minimum value of the excess adsorption capacity was $0.00239 \mathrm{mmol} / \mathrm{m}^{2}$ when the pore size was $20 \mathrm{~nm}$. The conclusions illustrate that the methane adsorption capacity in chlorite micropores increased with an increase in pore size, whereas that in chlorite mesopores decreased with an increase in the pore size.

The average isosteric heat of methane in chlorite pores with different pore sizes is shown in Fig. 5. It is seen that the methane isosteric heat decreased gradually with an increase in pore size. The isosteric heat for a pore size of $1 \mathrm{~nm}$ was the maximum value $(13.6 \mathrm{~kJ} / \mathrm{mol})$, and the average isosteric heat for a pore size of $20 \mathrm{~nm}$ was the minimum value $(6.12 \mathrm{~kJ} / \mathrm{mol})$. Experimentally, Ji et al. (2012a, b) found that the average isosteric heat of methane adsorption on chlorite was $9.4 \mathrm{~kJ} / \mathrm{mol}$. Although there are differences between the simulated and experimental results, they also showed similarities to a certain extent. This result may be related to the differences of research methods and samples. The pore size in the experiments is distributed continuously between $20 \mathrm{~nm}$ and $100 \mathrm{~nm}$ (Ji et al. 2012a, b), and the methane isosteric heat obtained from the experiment reflects the synthesis results obtained for the sample with a continuous distribution of pore sizes. However, the pore skeletons of chlorite in the simulation have a single pore size, and the methane isosteric heat obtained from the simulation reflects the results for a single pore and changes with pore size. In addition, the isosteric heat of adsorption of methane in chlorite pores with different pore sizes was less than $42 \mathrm{~kJ} / \mathrm{mol}$, demonstrating that the methane adsorption on chlorite is of the physical adsorption type. This conclusion is in accord with previous studies that suggested the methane is adsorbed on chlorite by physical adsorption (Ji et al. 2012a, b; Fan et al. 2014; Tang and Fan 2014; Liang et al. 2016).
Table 3 Simulation results of methane adsorption on chlorite for different pore sizes

\begin{tabular}{llllll}
\hline$H, \mathrm{~nm}$ & $n_{\text {exc-max }}, \mathrm{mmol} / \mathrm{m}^{2}$ & $p_{\text {max }}, \mathrm{MPa}$ & $H, \mathrm{~nm}$ & $n_{\text {exc-max }}, \mathrm{mmol} / \mathrm{m}^{2}$ & $p_{\text {max }}, \mathrm{MPa}$ \\
\hline 1 & 0.003276 & 18 & 6 & 0.002839 & 16 \\
1.5 & 0.003417 & 18 & 8 & 0.002614 & 14 \\
2 & 0.003505 & 18 & 10 & 0.002496 & 16 \\
3 & 0.003199 & 18 & 15 & 0.002340 & 14 \\
4 & 0.003016 & 16 & 20 & 0.002178 & 14 \\
\hline
\end{tabular}




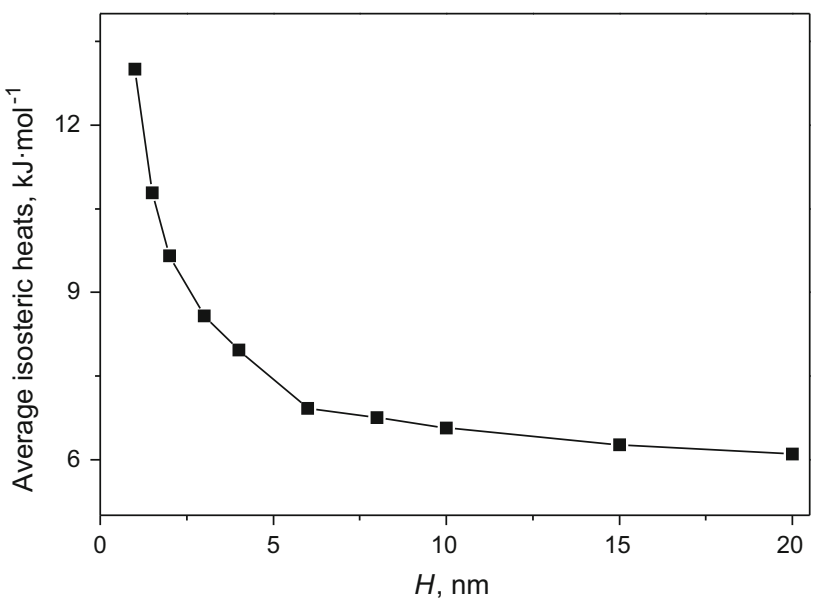

Fig. 5 Average methane isosteric heat in a chlorite pore with different pore sizes

According to the simulation results, we obtained the potential energy distribution of methane and chlorite. The methane and chlorite potential energy distribution curves for different pressures (pore size of $4 \mathrm{~nm}$ ) are presented in Fig. 6a. It can be noted that the curve transforms the twin peaks into a unimodal distribution with the increase in the pressure. At the same time, as the pressure is increased, the potential energy distribution curves of methane and chlorite gradually moved to the left. Additionally, the most probable potential energy of methane and chlorite gradually decreased, that is, the most probable potential energy changed from -0.209 to $-6.485 \mathrm{~kJ} / \mathrm{mol}$ as the pressure increased from 2 to $36 \mathrm{MPa}$. This indicates that methane adsorption occurring in chlorite pores gradually changes from higher-energy adsorption sites to lower-energy adsorption sites with the increase in pressure and that the adsorption state of methane molecules in chlorite pores under low pressure is not as stable as that under highpressure conditions. In addition, the potential energy distribution curves of methane and chlorite with different pore sizes under a pressure of $20 \mathrm{MPa}$ are presented in Fig. $6 \mathrm{~b}$. Examination of Fig. $6 \mathrm{~b}$ shows that the potential energy distribution curves of methane and chlorite gradually moved to the right with the increase in pore size and the most probable potential energy of methane and chlorite gradually increased, that is, the most probable potential energy changed from -11.92 to $-3.56 \mathrm{~kJ} / \mathrm{mol}$ when the pore size increased from $1 \mathrm{~nm}$ to $20 \mathrm{~nm}$. This suggests that methane adsorption occurring in chlorite pores gradually changed from lower-energy adsorption sites to higher-energy adsorption sites as the pore size increased, and the methane adsorption capacity in chlorite micropores was stronger than that in macropores.

\subsection{Influence of different temperatures}

The excess adsorption isotherms of methane for different temperatures (pore size of $4 \mathrm{~nm}$ ) are listed in Fig. 7. It can be seen that the methane excess adsorption capacity decreased with increasing temperature under the same pressure; this may be due to methane adsorption on chlorite being of the physical adsorption type. When the temperature increases, the thermal motion of methane molecules would increase, resulting in an increase in the mean kinetic energy of methane molecules, generating a sufficiently large force to escape from the chlorite pore wall easily, thus causing a reduction in the methane adsorption capacity. This conclusion is in accord with the results of the isothermal adsorption experiments performed by Ji et al. (2012a, b), suggesting that the methane adsorption capacity on chlorite decreased with increasing temperature.
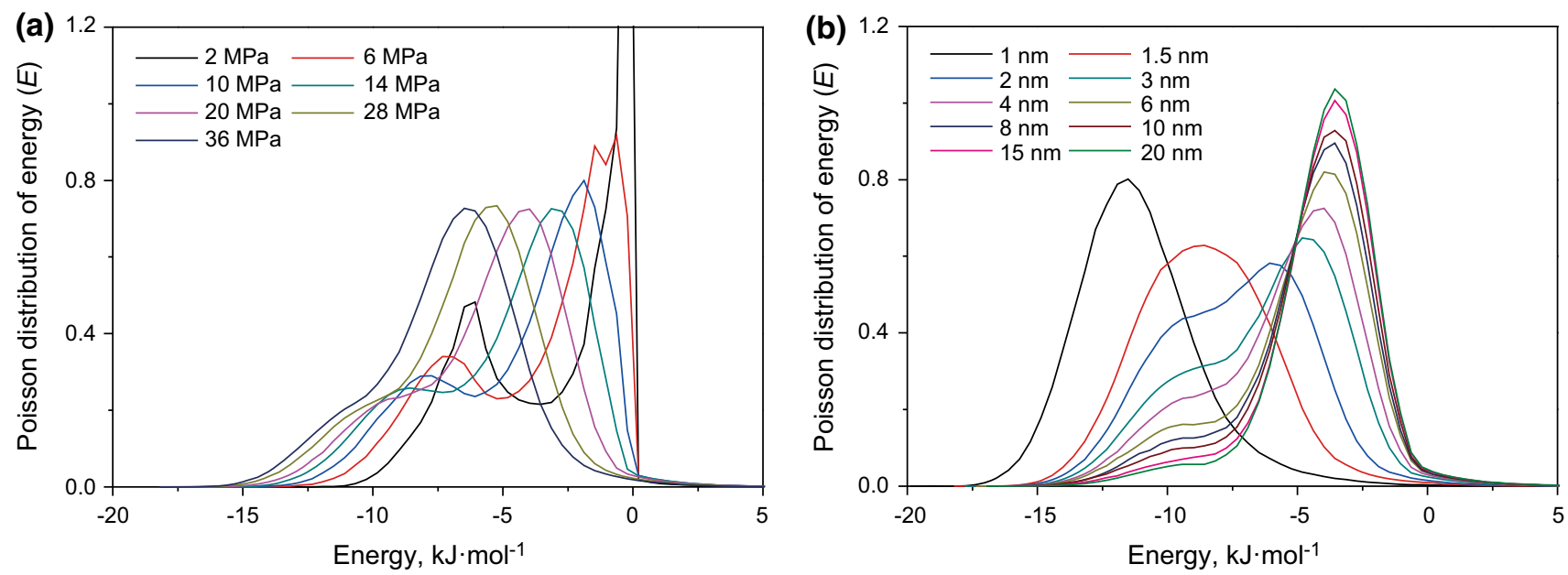

Fig. 6 Potential energy distribution curves of methane and chlorite for different pressures (pore size of $4 \mathrm{~nm}$ ) (a) and different pore sizes (pressure of $20 \mathrm{MPa}$ ) (b) 


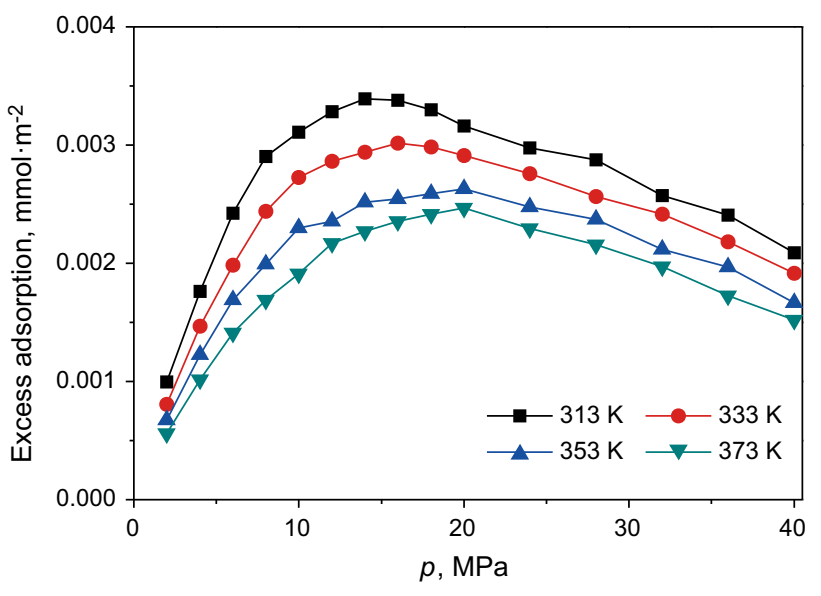

Fig. 7 Excess adsorption isotherms of methane for different temperatures (pore size of $4 \mathrm{~nm}$ )

Figure 8 shows the average methane isosteric heat in chlorite pores for different temperatures (pore size of $4 \mathrm{~nm}$ ). We observe that the average isosteric heat of methane decreased with increasing temperature, indicating that the interactions between methane molecules and chlorite became weaker with increasing temperature, resulting in a decrease in the methane adsorption capacity. In the range of the simulated temperatures, the value of the average isosteric heat of methane in a chlorite pore with the pore size of $4 \mathrm{~nm}$ is between 7.59 and $8.21 \mathrm{~kJ} / \mathrm{mol}$ (less than $42 \mathrm{~kJ} / \mathrm{mol}$ ), illustrating that the adsorption of methane in the chlorite pores is due to physical adsorption. These findings indicate that methane adsorption on chlorite is exothermic and the increase in temperature is not conducive for methane adsorption on chlorite. The potential energy distribution curves between methane and chlorite at different temperatures (pore size of $4 \mathrm{~nm}$ ) are shown in Fig. 9. When the temperature increased, the potential energy distribution curve of methane and chlorite gradually

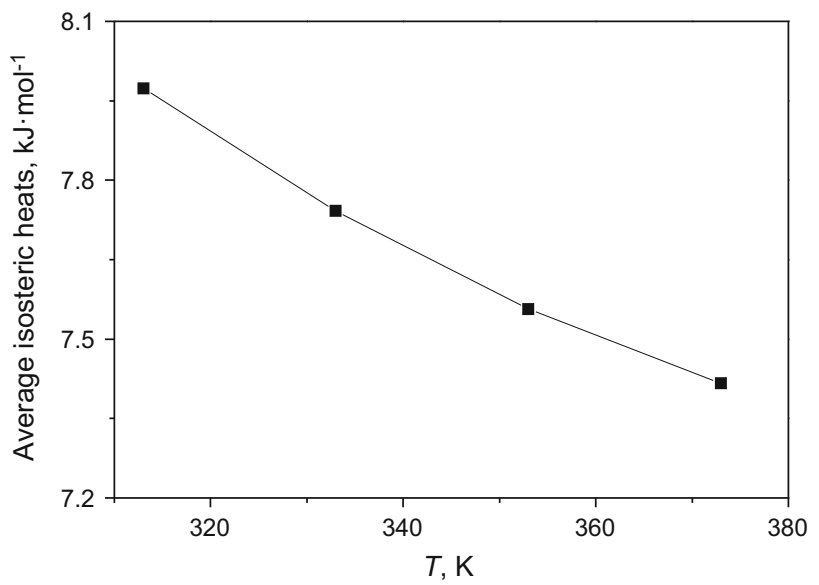

Fig. 8 Average isosteric heats of methane for different temperatures (pore size of $4 \mathrm{~nm}$ ) moved to the right. Furthermore, the most probable potential energy of methane and chlorite gradually increased, that is, the most probable potential energy changed from -4.393 to $-3.138 \mathrm{~kJ} / \mathrm{mol}$ when the temperature increased from 313 to $373 \mathrm{~K}$. This finding suggests that the adsorption sites of methane molecules in chlorite pores gradually change from lower-energy adsorption sites to higher-energy adsorption sites with increasing temperature, causing the reduction in the methane adsorption capacity.

\subsection{Influence of different water contents}

To investigate the influence of water on the methane adsorption in chlorite pores, three simulation projects considering three water contents $(\mathrm{wt} \%=$ the water molecules mass/the chlorite mass) were carried out. First the adsorption sites of water molecules in the slit-like chlorite pores need to be determined by using the annealing simulation method. The distribution of the different water contents in the chlorite pores is given in Fig. 10. In addition, the size of the chlorite pores is $4 \mathrm{~nm}$ and the temperature is $333 \mathrm{~K}$ in simulation.

Examination of Fig. 10 shows that water molecules occupied the chlorite pore walls in a directional manner, and the oxygen atoms of the water molecules were close to or pointed to the surface of the chlorite pore wall or hydrogen atoms of the surrounding water molecules, with the hydrogen atoms located at a distance from the surface of the chlorite pore wall. This may be due to the positive charges of the aluminium and silicon atoms on the surface of the chlorite pore wall and the negative charge of the oxygen atoms of the water molecule, causing a pattern in which the oxygen atoms of the water molecules are close to or point to the surface of the chlorite pore wall. This phenomenon arises from the Coulomb and van der Waals

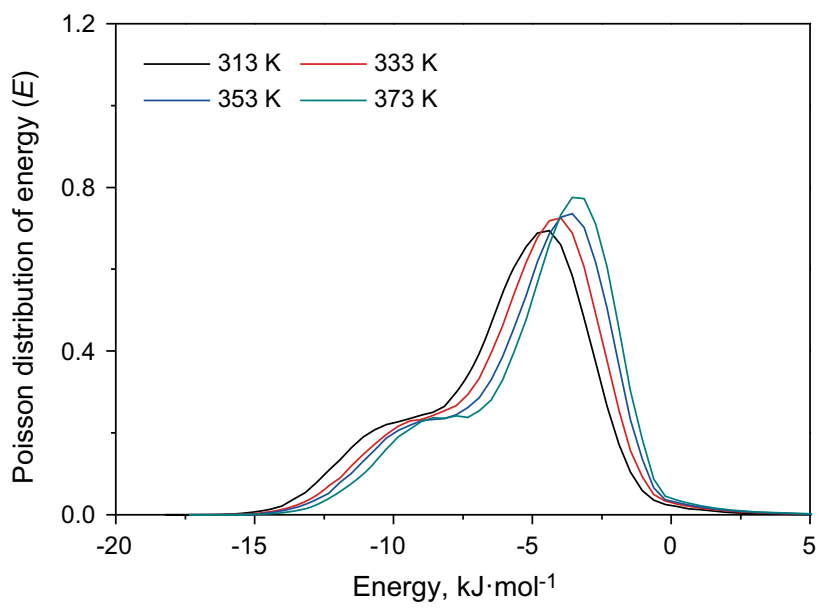

Fig. 9 Potential energy distribution curves of methane and chlorite at different temperatures (pore size of $4 \mathrm{~nm}$ ) 

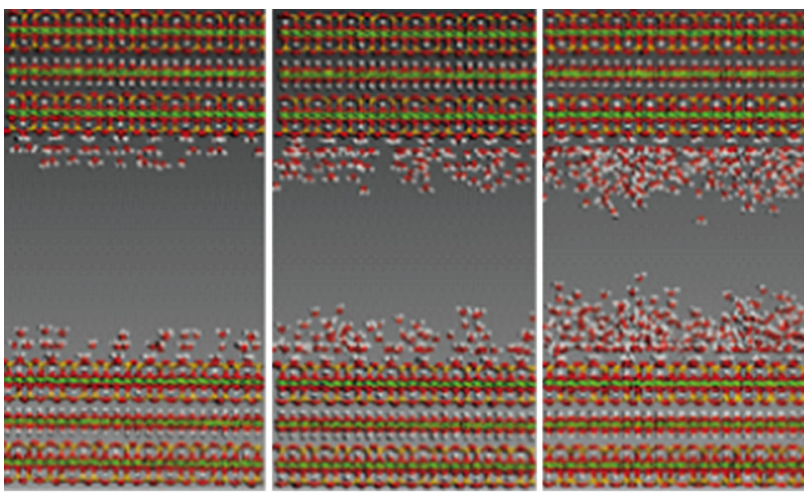

$2 \%$ (149 number) $4 \%$ (298 number) $8 \%$ (596 number)

Fig. 10 Distribution of different water contents in chlorite pores (the number in parentheses represents the number of water molecules)

force interactions between water molecules and chlorite, resulting in the aggregation of water molecules in the chlorite pore. In addition, due to the hydrogen bonding interaction, the oxygen atoms of the water molecules point to the hydrogen atoms of surrounding water molecules. All of the data indicate that the water molecules are adsorbed on the surface of the pore walls and occupy the adsorption space of the methane molecules in the form of aggregation.

Figure 11 shows the methane excess adsorption isotherms for different water contents. It can be seen that the methane excess adsorption capacity on chlorite is reduced when the water contents increased under the same temperature and pressure, implying that water molecules inhibit methane adsorption on chlorite. This conclusion is in agreement with a previous study of methane adsorption on montmorillonite (Jin and Firoozabadi 2013, 2014), indicating that water reduced the methane adsorption capacity on montmorillonite. The potential energy distribution curves of methane and chlorite for different water contents are shown in Fig. 12. Inspection of Fig. 12 shows

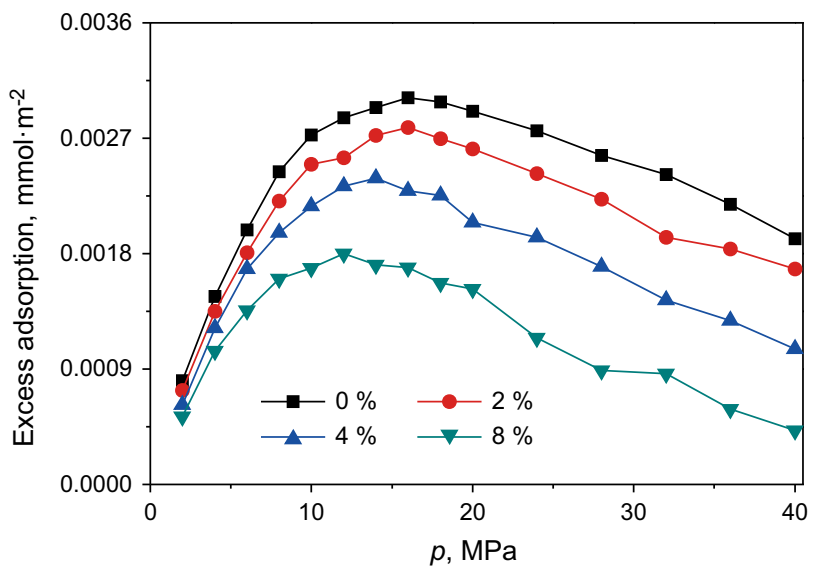

Fig. 11 Excess adsorption isotherms of methane for different water contents that the curves have two peaks, with the main peak lying in the higher-energy area and the secondary peak located in the lower-energy area. The most probable potential energy of methane and chlorite did not change significantly with the increase in the water contents, indicating that the methane molecules in the higher-energy adsorption sites could not be occupied with the change of water contents. However, the secondary peak of the potential energy distribution curve gradually became broad, implying that the water molecules occupy the lower-energy adsorption sites of methane molecules. It can be deduced that water molecules mainly occupied lower-energy adsorption sites on the chlorite pore walls instead of higher-energy adsorption sites, illustrating that the water molecules and methane molecules compete with each other for adsorption space and adsorption sites. Therefore, the adsorption space and adsorption sites occupied by water molecules decreased the adsorption space and adsorption sites of methane molecules, leading to a decrease in the methane adsorption capacity.

\subsection{Influence of different mole fractions of nitrogen}

To investigate the influence of mole fraction of nitrogen on competitive adsorption of nitrogen and methane in the chlorite pores, five simulation projects considering five mole fractions of nitrogen in the methane/nitrogen binary gas mixture $\left(y_{\mathrm{CH} 4}=80 \%\right.$ means that the mole fraction of methane is $80 \%$ while the mole fraction of nitrogen is $20 \%$ ) would be carried out. The size of the chlorite pores is $4 \mathrm{~nm}$ and the temperature is $333 \mathrm{~K}$ in the simulation.

The excess adsorption isotherms of methane for different mole fractions of nitrogen are shown in Fig. 13. The methane excess adsorption capacity decreased with the increase in the nitrogen mole fraction at the same temperature and pressure, indicating that a lower mole fraction

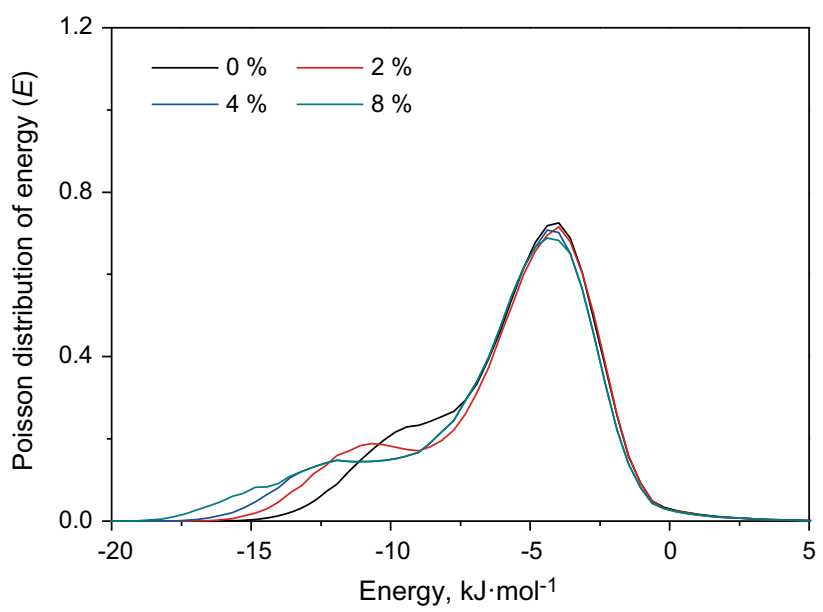

Fig. 12 Potential energy distribution curves of methane and chlorite for different water contents 
of the methane in the methane/nitrogen binary gas mixture leads to a smaller methane adsorption capacity on chlorite.

In the adsorption system of the methane/nitrogen binary gas mixture, the potential energy distribution curves for different mole fractions of nitrogen are presented in Fig. 14. It can be seen that the most probable potential energy of methane and chlorite under different nitrogen mole fractions was smaller than that of the nitrogen, demonstrating that the potential energy distribution between methane and chlorite was different from that between nitrogen and chlorite, that is, the methane adsorption occurring on the chlorite pore walls was due to the lower-energy adsorption sites, whereas nitrogen adsorption occurred in higher-energy adsorption sites, illustrating that nitrogen adsorption on chlorite in the adsorption system of the methane/nitrogen binary gas mixture was less stable than that of methane. Figure 15 (the distributions of methane and nitrogen on the surface of chlorite) also illustrates this conclusion. Figure 15 shows that the methane molecules and nitrogen molecules on the chlorite surface were distributed among different adsorption sites.

Furthermore, we found that the interactions between methane and nitrogen led to a change of the potential energy distribution curves of methane and chlorite. At the same time, the potential energy distribution curve of methane and chlorite gradually moved to the right and the most probable potential energy of methane and chlorite gradually increased with increasing nitrogen mole fraction. Namely, the methane adsorption gradually changed from lower-energy adsorption sites to higher-energy adsorption sites with the increase in the nitrogen mole fraction, resulting in a decrease in the methane adsorption capacity on chlorite, implying that the nitrogen adsorption occurring in the chlorite pores led to the change of the adsorption site of methane molecules and the reduction of the adsorption

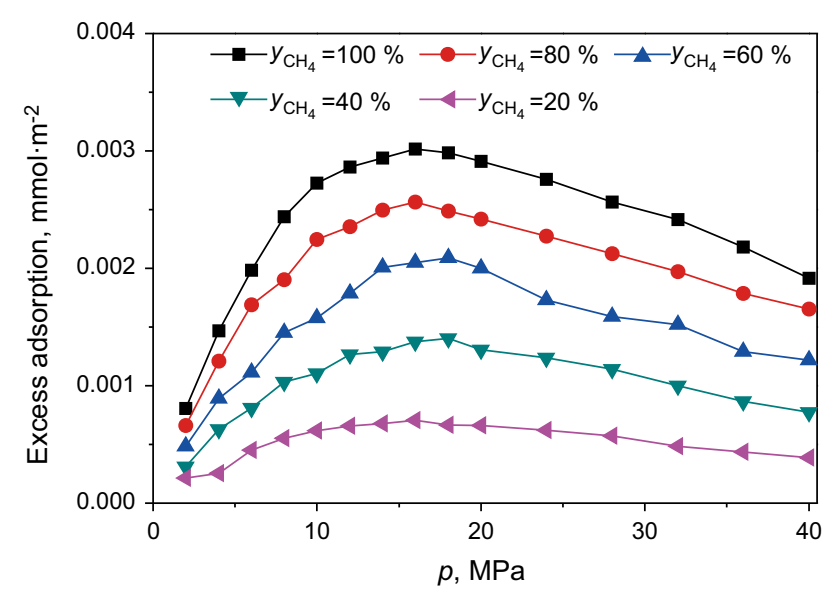

Fig. 13 Excess adsorption isotherms of methane on chlorite for different mole fractions of nitrogen

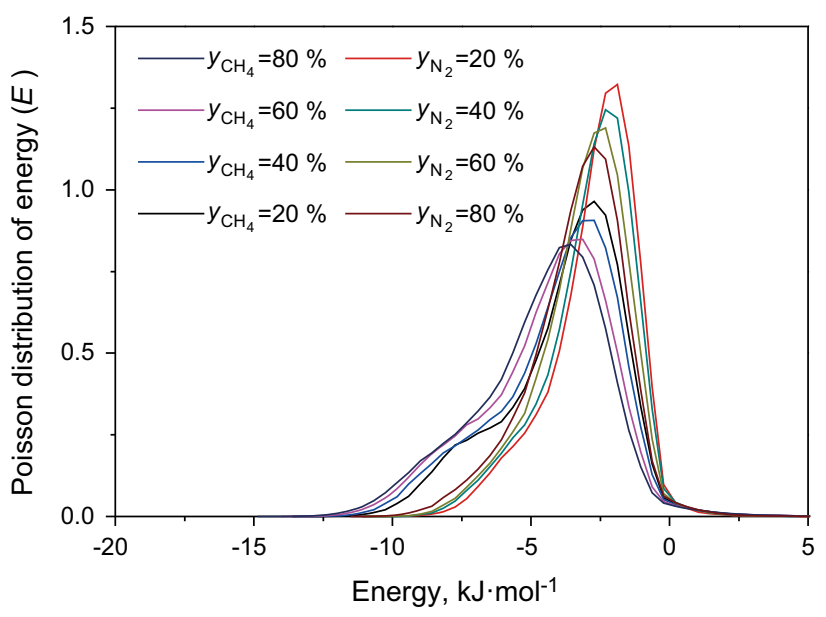

Fig. 14 Potential energy distribution curves for different mole fractions of nitrogen

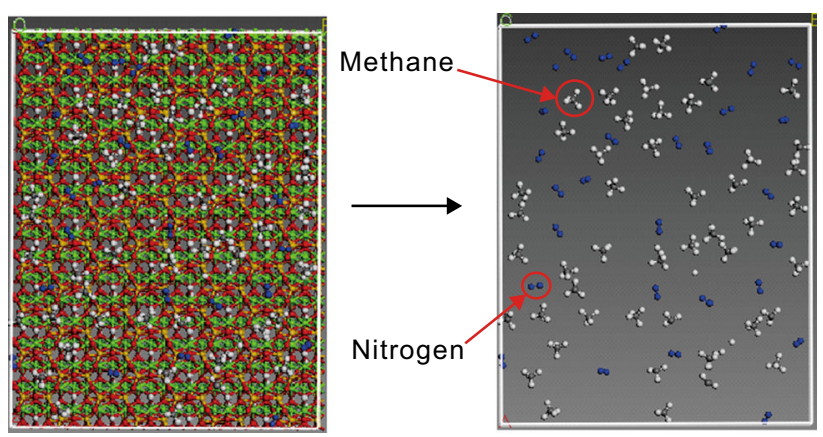

Fig. 15 Distributions of methane and nitrogen on the surface of chlorite (right does not include the chlorite cell)

space for methane molecules. Hence, in the adsorption system of the methane/nitrogen binary gas mixture, the methane adsorption capacity on chlorite is greater than that of nitrogen. According to the previous analysis, the methane adsorption capacity decreased with the increase in the mole fraction of nitrogen due to the decrease in the methane mole fraction in the gas phase, the change of the adsorption sites of the methane molecules and the reduction in the adsorption space of the methane molecules.

\subsection{Influence of different mole fractions of carbon dioxide}

To investigate the influence of the mole fraction of carbon dioxide on competitive adsorption of carbon dioxide and methane in the chlorite pores, simulations with five mole fractions of carbon dioxide in the carbon dioxide/methane binary gas mixture $\left(y_{\mathrm{CH} 4}=80 \%\right.$ means that the mole fraction of methane is $80 \%$ while the mole fraction of carbon dioxide is $20 \%$ ) were carried out. The size of the chlorite pores is $4 \mathrm{~nm}$, and the temperature is $333 \mathrm{~K}$ in these simulations. 
Excess adsorption isotherms of methane for different mole fractions of carbon dioxide are shown in Fig. 16. It can be seen that the methane excess adsorption capacity decreased as the carbon dioxide mole fraction increased at the same pressure and temperature, indicating that the smaller methane mole fraction in the carbon dioxide/ methane binary gas mixture led to lower methane adsorption capacity.

In the adsorption system of the carbon dioxide/methane binary gas mixture, the potential energy distribution curves for different mole fractions of carbon dioxide are shown in Fig. 17. It can be seen that the most probable potential energy of methane and chlorite for different carbon dioxide mole fractions was higher than that of carbon dioxide, suggesting that the potential energy distribution between methane and chlorite was different from that between carbon dioxide and chlorite. That is, carbon dioxide adsorption on the chlorite pore walls occurred in the lowerenergy adsorption sites, whereas methane adsorption was located in higher-energy adsorption sites, implying that methane adsorption on chlorite in the adsorption system of the carbon dioxide/methane binary gas mixture was less stable than that of carbon dioxide. Figure 18 (the distributions of methane and carbon dioxide on the chlorite surface) also illustrates this conclusion. Figure 18 shows that methane and carbon dioxide molecules on the chlorite surface were distributed among different adsorption sites.

Furthermore, we also observed that the interactions between methane and carbon dioxide could change the potential energy distribution curves of methane and chlorite. At the same time, the potential energy distribution curve of methane and chlorite gradually moved to the right and the most probable potential energy of methane and chlorite gradually increased with increasing carbon dioxide mole fraction, meaning that the methane adsorption sites gradually changed from lower-energy adsorption sites to

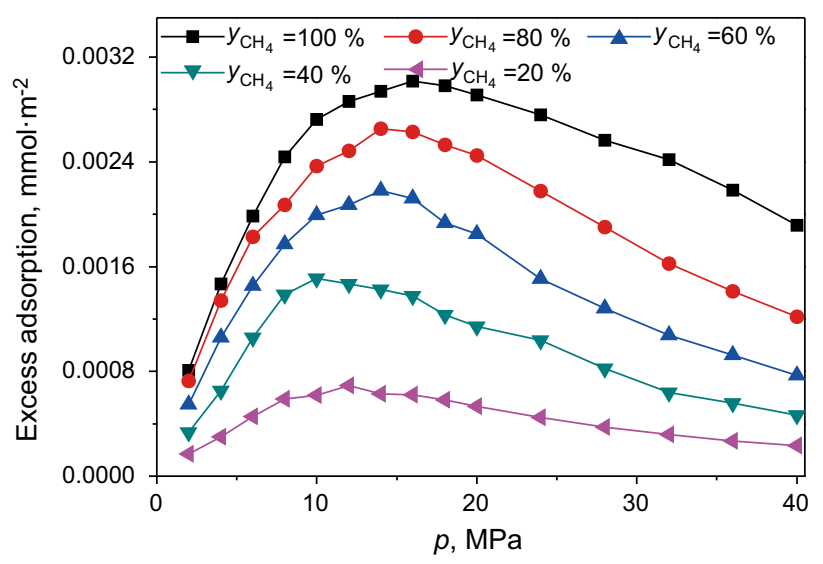

Fig. 16 Excess adsorption isotherms of methane in chlorite pores for different carbon dioxide mole fractions

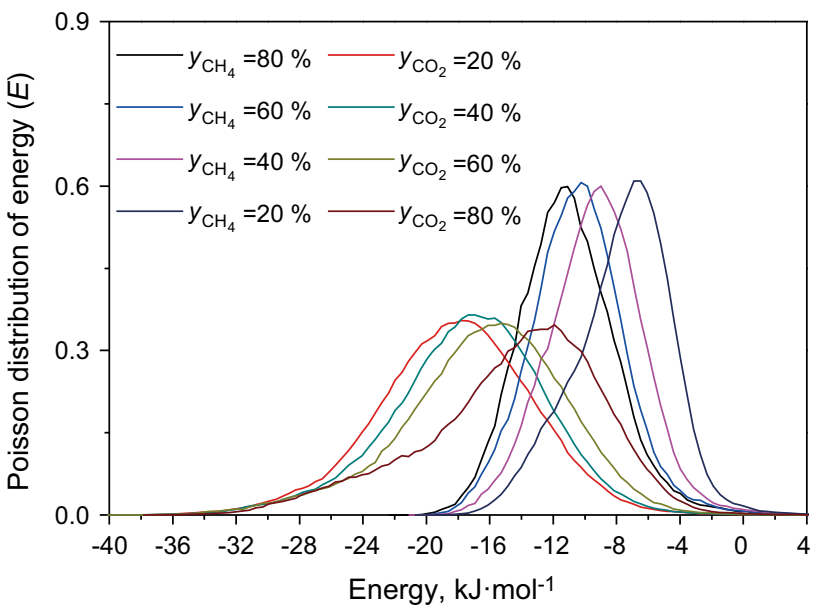

Fig. 17 Potential energy distribution curves for different mole fractions of carbon dioxide

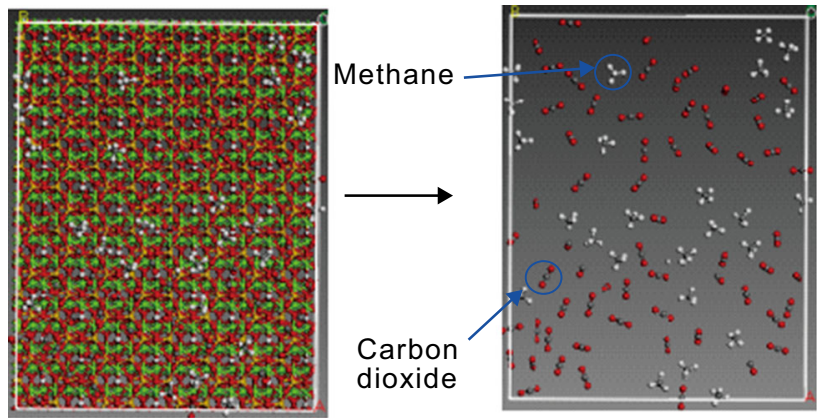

Fig. 18 Distributions of methane and carbon dioxide on the surface of chlorite (right does not include the chlorite cell)

higher-energy adsorption sites with the increasing carbon dioxide mole fraction, leading to a reduction in the methane adsorption capacity on chlorite. This phenomenon demonstrates that carbon dioxide adsorption occurring in chlorite pores results in a change of the adsorption site of methane molecules and a reduction in their adsorption space. Thus, the carbon dioxide adsorption capacity on chlorite is greater than that of methane in the carbon dioxide/methane binary gas mixture adsorption system. Based on the previous analysis, the methane adsorption capacity decreased with the increase in the carbon dioxide mole fraction, resulting in a reduction in the methane mole fraction in the gas phase, a change of the adsorption sites of the methane molecules and a reduction in the methane adsorption space.

\section{Conclusions}

First, the average methane isosteric heat decreased with increasing pore size, which was smaller than $42 \mathrm{~kJ} / \mathrm{mol}$ in the chlorite-methane adsorption system, suggesting that 
methane adsorbed on the chlorite through a physical adsorption.

Second, the methane adsorption capacity in chlorite pores increased with the increase in pressure or decrease in the pore size. In chlorite micropores, the methane adsorption capacity increased with the increase in pore size, showing an opposite trend to the findings for mesopores.

In addition, the isosteric heat of methane decreased with the increase in temperature. At that time, the methane adsorption site changed from lower-energy adsorption sites to higher-energy adsorption sites, leading to the decline of the methane adsorption capacity. Water molecules in the chlorite pores occupied the pore wall in a directional manner and occupied the adsorption sites and adsorption space of methane molecules, causing a decrease in the methane adsorption capacity.

Finally, in a system of methane with nitrogen or carbon dioxide, the order of the potential energy between gas and chlorite is as follows: nitrogen $>$ methane $>$ carbon dioxide, implying that the adsorption capacity of carbon dioxide on chlorite is larger than that of methane and that the adsorption capacity of methane is greater than that of nitrogen. An increase in the mole fraction of nitrogen or carbon dioxide would lead to a change of the methane adsorption sites as well as a reduction in the methane adsorption space and the mole fraction of methane in the gas phase, resulting in a decrease in the methane adsorption capacity.

Acknowledgements This research was supported by the United Fund Project of National Natural Science Foundation of China (Grant No. U1262209) and the National Natural Science Foundation of China (Grant No. 41602155), and the Young Scholars Development Fund of SWPU (No. 201599010137).

Open Access This article is distributed under the terms of the Creative Commons Attribution 4.0 International License (http://crea tivecommons.org/licenses/by/4.0/), which permits unrestricted use, distribution, and reproduction in any medium, provided you give appropriate credit to the original author(s) and the source, provide a link to the Creative Commons license, and indicate if changes were made.

\section{References}

Berendsen HJC, Grigera JR, Straatsma TP. The missing term in effective pair potentials. J Phys Chem. 1987;91(24):6269-71. doi: $10.1021 / \mathrm{j} 100308 \mathrm{a} 038$.

Curtis JB. Fractured shale gas systems. AAPG Bull. 2002;86(11):1921-38. doi:10.1306/61eeddbe-173e-11d7-8645000102c1865d.

Cygan RT, Liang JJ, Kalinichev AG. Molecular models of hydroxide, oxyhydroxide, and clay phases and the development of a general force field. J Phys Chem B. 2004;108(4):1255-66. doi:10.1021/ jp0363287.

Fan EP, Tang SH, Zhang CL, Guo QL, Sun CG. Methane sorption capacity of organics and clays in high-over matured shale-gas systems. Energy Explor Exploit. 2014;32(6):927-42. doi:10. 1260/0144-5987.32.6.927.

Gasparik M, Bertier P, Gensterblum Y, et al. Geological controls on the methane storage capacity in organic-rich shales. Int $\mathrm{J}$ Coal Geol. 2014;123:34-51. doi:10.1016/j.coal.2013.06.010.

Harris JG, Yung KH. Carbon dioxide's liquid-vapor coexistence curve and critical properties as predicted by a simple molecular model. J Phys Chem. 1995;99(31):12021-4. doi:10.1021/ j100031a034.

Ji LM, Qua JL, Zhang TW, Xia YQ. Relationship between methane adsorption capacity of clay minerals and micropore volume. Earth Sci (J China Univ Geosci). 2012a;37(5):1043-50. doi:10. 3799/dqkx.2012.111 (in Chinese).

Ji LM, Zhang TW, Milliken KL, Qua JL, Zhang XL. Experimental investigation of main controls to methane adsorption in clay-rich rocks. Appl Geochem. 2012b;27:2533-45. doi:10.1016/j.apgeo chem.2012.08.027.

Jin ZH, Firoozabadi A. Methane and carbon dioxide adsorption in clay-like slit pores by Monte Carlo simulations. Fluid Phase Equilib. 2013;360:456-65. doi:10.1016/j.fluid.2013.09.047.

Jin ZH, Firoozabadi A. Effect of water on methane and carbon dioxide sorption in clay minerals by Monte Carlo simulations. Fluid Phase Equilib. 2014;382:10-20. doi:10.1016/j.fluid.2014. 07.035 .

Joswig W, Fuess H, Rothbauer R, et al. A neutron diffraction study of a one-layer triclinic chlorite (penninite). Am Mineral. 1980;65(3-4):349-52.

Liang LX, Luo DX, Liu XJ, Xiong J. Experimental study on the wettability and adsorption characteristics of Longmaxi Formation shale in the Sichuan Basin, China. J Nat Gas Sci Eng. 2016;33:1107-18. doi:10.1016/j.jngse.2016.05.024.

Liang LX, Xiong J, Liu XJ. Mineralogical, microstructural and physiochemical characteristics of organic-rich shales in the Sichuan Basin, China. J Nat Gas Sci Eng. 2015;26:1200-12. doi:10.1016/j.jngse.2015.08.026.

Liu XJ, Xiong J, Liang LX. Investigation of pore structure and fractal characteristics of organic-rich Yanchang Formation shale in central China by nitrogen adsorption/desorption analysis. J Nat Gas Sci Eng. 2015;22:62-72. doi:10.1016/j.jngse.2014.11.020.

Martin MG, Siepmann JI. Transferable potentials for phase equilibria.1. United-atom description of n-alkanes. J Phys Chem B. 1998;102(14):2569-77. doi:10.1021/jp972543+.

Potoff JJ, Siepmann JI. Vapor-liquid equilibria of mixtures containing alkanes, carbon dioxide, and nitrogen. AIChE J. 2001;47(7):1676-82. doi:10.1002/aic.690470719.

Rexer TF, Benham MJ, Aplin AC, Thomas KM. Methane adsorption on shale under simulated geological temperature and pressure conditions. Energy Fuels. 2013;27(6):3099-109. doi:10.1021/ ef400381v.

Soave G. Equilibrium constants from a Modified Redlich-Kwong equation of state. Chem Eng Sci. 1972;27(6):1197-203. doi:10. 1016/0009-2509(72)80096-4.

Sui HG, Yao J, Zhang L. Molecular simulation of shale gas adsorption and diffusion in clay nanopores. Computation. 2015;3(4):687-700. doi:10.3390/computation3040687.

Sun RY, Zhang YF, Fan KK, Shi YH, Yang SK. Molecular simulation of adsorption characteristics of clay minerals in shale. CIESC Journal. 2015;66(6):2118-22. doi:10.11949/j.issn.0438-1157. 20141766 (in Chinese).

Talu O, Myers AL. Molecular simulation of adsorption: Gibbs dividing surface and comparison with experiment. AIChE J. 2001;47(5):1160-8. doi:10.1002/aic.690470521.

Tang SH, Fan EP. Methane adsorption characteristics of clay minerals in organic-rich shales. J China Coal Soc. 2014;39(8):1700-6. doi:10.13225/j.cnki.jccs.2014.9015 (in Chinese). 
Titiloye JO, Skipper NT. Monte Carlo and molecular dynamics simulations of methane in potassium kaolinite clay hydrates at elevated pressures and temperatures. J Colloid Interface Sci. 2005;282(2):422-7. doi:10.1016/j.jcis.2004.08.131.

U.S. Energy Information Administration (EIA). Technically Recoverable Shale Oil and Shale Gas Resources: An Assessment of 137 Shale Formations in 41 Countries Outside the United States. http://www.eia.gov/analysis/studies/worldshalegas. 24 Sep 2013.

Xiong J, Liu XJ, Liang LX. Experimental study on the pore structure characteristics of the Upper Ordovician Wufeng Formation shale in the southwest portion of the Sichuan Basin, China. J Nat Gas Sci Eng. 2015a;22:530-9. doi:10.1016/j.jngse.2015.01.004.

Xiong J, Liu XJ, Liang LX, Lei M. Improved Dubibin-Astakhov model for shale gas supercritical adsorption. Acta Pet Sinica. 2015b;36(7):849-57. doi:10.7623/syxb2015.07.009 (in Chinese).
Xiong J, Liu XJ, Liang LX. Molecular simulation on the adsorption behaviors of methane in montmorillonite slit pores. Acta Pet Sinica. 2016;37(8):1021-9. doi:10.7623/syxb201608008 (in Chinese).

Yang F, Ning ZF, Zhang R, Zhao HW, Krooss BM. Investigations on the methane sorption capacity of marine shales from Sichuan Basin, China. Int J Coal Geol. 2015;146:104-17. doi:10.1016/j. coal.2015.05.009.

Yang X, Zhang C. Structure and diffusion behavior of dense carbon dioxide fluid in clay-like slit pores by molecular dynamics simulation. Chem Phys Lett. 2005;407(4):427-32. doi:10.1016/j. cplett.2005.03.118.

Zeng QH, Yu AB, Lu GQ, Standish RK. Molecular dynamics simulation of organic-inorganic nanocomposites: layering behavior and interlayer structure of organoclays. Chem Mater. 2003;15(25):4732-8. doi:10.1021/cm0342952. 